\title{
Sincronia entre o regime de vazante do rio e o comportamento de nidificaçào da tartaruga da Amazônia Podocnemis expansa (Testudinata: Pelomedusidae) (1)
}

\author{
Cleber J. R. Alho ${ }^{(2)}$ \\ Luiz F. M. Pádua ${ }^{(3)}$
}

\begin{abstract}
Resumo
Há uma sincronização entre a vazante e o desencadeamento do comportamento de nidificação da tartaruga da Amazônia Podocnemis expansa. O comportamento de nidificação só começa quando o nível da água se estabiliza em seu nivel mais baixo. A imprevisibilidade dos níveis de água no rio Trombetas, um tributário do Amazonas, no Pará, é um fator seletivo importante que influencia a data e a escolha do local da postura de $\mathbf{P}$. expansa. A cheia rápida e imprevisível (conhecida como repiquete) matou em 1980 99\% dos embriōes nos ovos em contraste com as estações de nidificação de 1978, 1979 e 1981 quando $95 \%$ dos ovos eclodiram com sucesso.
\end{abstract}

\section{INTRODUÇÃo}

Carr \& Giovannoli (1957), Vanzolini (1967); Alho et al. (1979), Ehrenfeld (1979), Alho \& Pádua, 1982 reconhecem sete fases durante o comportamento de nidificação das tartarugas: (1) agregação da população nas águas rasas próximas à praia de nidificação; (2) subida à praia para exporem-se ao sol durante as horas quentes do dia; (3) subida à praia à noite com caminhada de vistoria e escolha do sítio de nidificação; (4) escavação do ninho; (5) postura; (6) preenchimento e compactação do ninho; (7) retorno à água. No início da estação de nidificação no Trombetas, um tributário do Amazonas, no Estado do Pará, as tartarugas adultas migram dos lagos localizados às margens do rio. A migração das tartarugas adultas, machos e fêmeas, coincide com o regime do rio, onde o início da vazante parece ser a causa próxima que estimula os animais a iniciarem sua migração para o local de nidificação (Alho \& Pádua, 1982). Durante a cheia, em julho, os adultos são encontrados nos lagos, onde a fiscalização do IBDF comumente apreende machos e fêmeas adultos capturados nos lagos. Em fins de setembro ou no início de outubro, as tartarugas são vistas agregando-se no rio. Machos e fêmeas têm sido aprendidos de capturadores ilegais que coletam os animais no rio, nessa época.

Após a fase de agregação, que é variável em tempo, em função do regime de vazante do rio, as fêmeas adultas começam o ritual de comportamento de nidificação. A desova é precedida de uma série de padrões de comportamento de seqüências integradas e movimentos estereotipados (Alho et al., 1979; Alho \& Pádua, 1982) .

C objetivo deste trabalho é o de mostrar evidências de uma sincronia existente entre 0 máximo de vazante do rio e o desencadeamento desses padrões de comportamento.

\section{LOCAL DE ESTUDO E MÉTODOS}

Os dados foram obtidos durante quatro estações de nidificação (outubro de 1978, 1979, 1980,1981 ; quatro períodos de eclosão (dezembro de $1978,1979,1980$ e 1981) e três períodos de cheia (julho de 1978, 1979 e 1980), na praia de areia, Tabuleiro Leonardo, no rio Trombetas $\left(1^{\circ} 20^{\prime} \mathrm{S}, 56^{\circ} 45^{\prime} \mathrm{W}\right)$ próximo à $\mathrm{Mi}$ neraçãc Santa Patrícia, Porto Trombetas, Estado do Pará, na Reserva Biológica do Rio Trombetás do IBDF. O regime de vazante do rio era controlado por réguas e piquetes colocados na

(1) $\rightarrow$ Trabalho realizado pela Universidade de Brasília e IBDF, com apoio da FINEP através do convênio IBDF/ FINEP n. $\mathrm{B} / 29 / 80 / 087 / 00 / 00$.

(2) - Universidade de Brasilia, Brasilia, DF.

(3) - Departamento de Parques Nacionais e Reservas Equivalentes, IBDF, Brasilia, DF. 
praia de nidificação. Todas as fases do comportamento de nidificação, desde a fase de agregação das tartarugas, eram observadas.

\section{RESUltadoS E DISCUSSÃo}

O's primeiros siriais de agregação são detectados por tartarugas que, vez por outra, vêm à tona, rapidamente, no meio do rio. Esta fase é difícil de ser vista a não ser pelo pessoal experiente e atento à observação. O nível de água continua descendo. Em seguida, em outubro, notam-se os primeiros sinais de agregação das tartarugas nas águas rasas. Assim que a vazante começa a estabilizar, na segunda parte de outubro, as tartarugas podem ser vistas acerca de 50 ou 100 metros distantes da praia, com suas cabeças fora d'água, orientadas no sentido do tabuleiro. Essa agregação é notada à noite e principalmente durante as horas mais quentes do dia. Alguns animais atingem a praia para se expor ao sol. Essa fase sń é notada quando a praia já está inteiramente de fora, a vazante atingindo seu ponto máximo, tendendo a estabilizar-se (Fig. 1.). Durante o dia, quando alguns indivíduos atingem a praia para se expor ao sol, algumas tartarugas ocasionalmente baixam a cabeça bruscamente. enfiando o nariz na areia, como que cheirando a areia da praia. Outras levantam suas cabeças, com o nariz para cima, como que cheirando o ar. Esse comportamento está provavelmente associado à sensibilização de temperatura. Em 1978 a estação de nidificação durou de 13 a 25 de outubro (Fig. 2). Cerca de 10 dias antes de a nidificação começar, as tartarugas foram observadas agregando-se próximo ao tabuleiro de postura, em frente ao local de nidificação. Em 1979 o periodo de nidificação começou a 5 de outubro cuando a vazante havia estabilizado mas as tartarugas pararam as atividades de nidificação em 9 de outubro, por causa de uma súbita enchente, conhecida na Amazônia como repiquete. Após a água ter-se estabilizado de novo no seu nível mais baixo o compor. tamento de nidificação começou de novo nos fins de outubro. Todos eses padrões de comportamento e suas fases estão descritos por Alho et al. (1979) e Alho \& Pádua (1982). Em 1980 , o repiquete ocorreu de novo no início da estação de eclosão, quando as tartarugas já haviam terminado a postura. A água encobriu o tabuleiro antes da eclosão, matando os ainda embriões. Em 1981 as tartarugas começaram a agregar-se no dia 20 de outubro, inicialmente nas águas profundas,. Nesse ano, houve uma vazante mais prolongada, retardando, em conseqüência, o início da nidificação. Quando as águas se estabilizaram, no início de novembro, as tartarugas desovaram diminuindo contudo o período de agregação nas águas rasas para apenas 4 dias (Fig. 2) .

Em 1978, 1979 e 1980 as tartarugas concentraram seus ninhos em duas áreas elevadas no tabuleiro de Lecnardo, tendo cada uma dessas elevações com cerca de $2.000 \mathrm{~m}^{2}$. Essas duas áreas mais elevadas estavam localizadas a 242 e $247 \mathrm{~cm}$ acima do nível da água, durante a estação de postura. As outras covas localizadas em pontos mais baixos situavam-se de 156 a $159 \mathrm{~cm}$, acima da água. Aplicando o índice de distribuição de Morisita (Morisita 1959, 1962, 1964), encontramos uma distribuição agregada de ninhos nas áreas de concentração (I-delta $=5.33 ; \mathrm{N}=25 ; \mathrm{n}=259 ; \mathrm{F}=47,61$ ). Onde I-delta é o índice de agregação proposto por Morisita, $\mathrm{N}$ é o número de amostras, isto é. o número de quadrats em que cada área elevada foi subdividida e $\mathrm{n}$ é o número de covas em todos os quadrats. Cada quadrat tinha $250 \mathrm{~m}^{2}$.

Em 1981, as tartarugas mudaram seu local de postura para uma área mais rio abaixo, mais para o interior do tabuleiro, em áreas mais altas.

O período médio de incubação é de 48 dias.

Em 1978 e 1979, o número médio de ovos postos per tartaruga numa amostra de $393 \mathrm{ni}$ nhos era de $91,5 \mathrm{com}$ uma postura mínima de 63 ovos por fêmeas e máxima de 134 ovos. Nesse período eclodiu uma média de 86 tartaruguinhas por cova com um valor mínimo de 53 tartaruguinhas por cova e máximo de 128 . O sucesso de eclosão foi assim, de $95 \%$, quando cerca de $400 \mathrm{mil}$ ovos foram postos em cada estação. Em 1980, somente 2.000 tartaruguinhas eclodiram das covas que lograram não ser inundadas. 

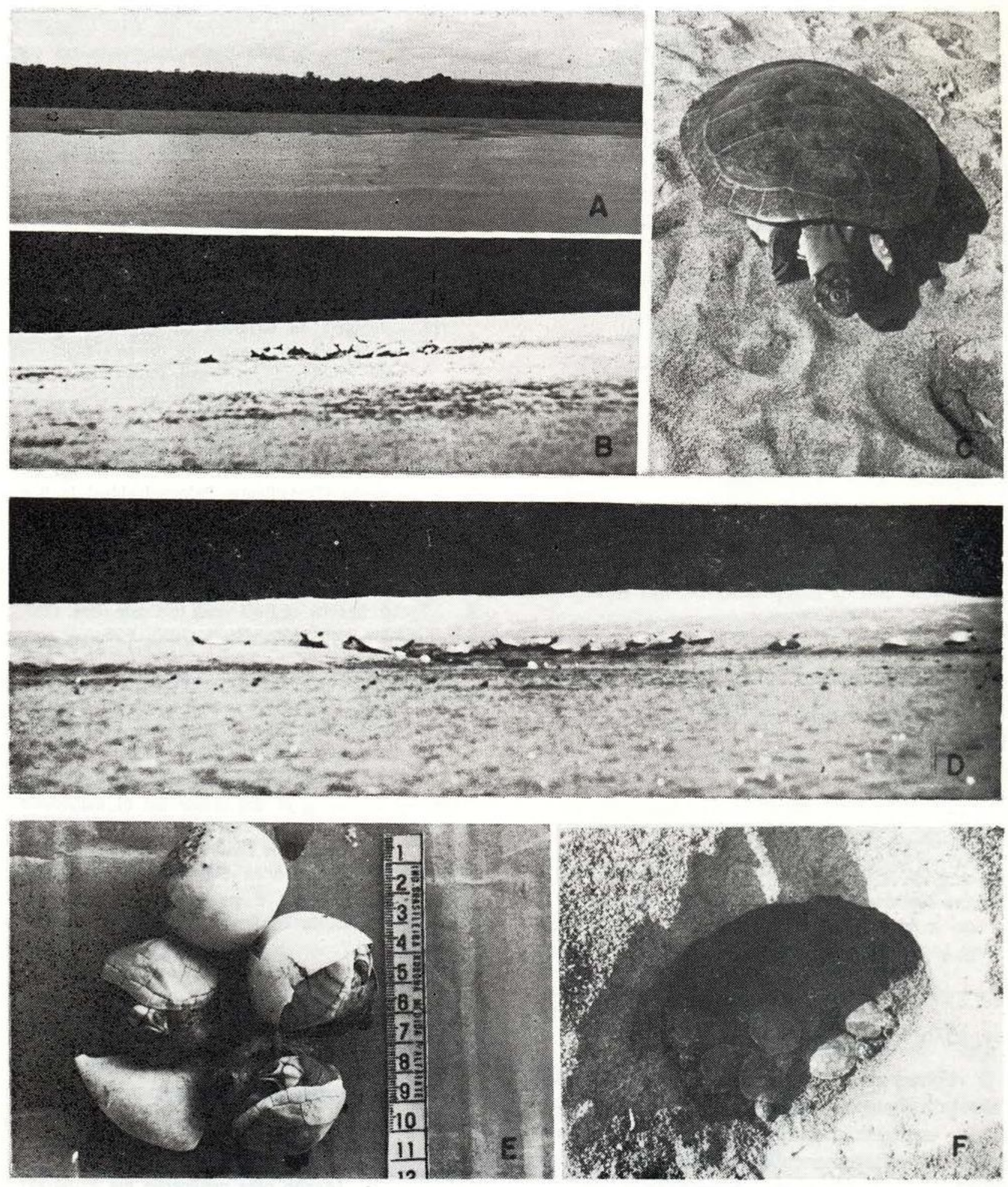

Fig. 1 - Fases importantes do comportamento de nidificação em sincronia com o regime de vazante do rio: A) o rio ainda está vazando e alguns animais só são vistos nas águas profundas; B) o rio atinge sua vazante máxima e as tartarugas são vistas agregando-se nas águas rasas junto ao tabuleiro de postura ou são vistas expondo-se ao sôl nas horas quentes do dia; C) um indivíduo em caminhada de vistoria antes da escolha do sítio do ninho; D) tartarugas expondo-se ao sol no local próximo onde irão desovar; E) tartaruguinhas quase prontas a eclodir mortas pelo repiquete de 1980; F) uma cova aberta com tartaruguinhas prontas a ganhar a água. 


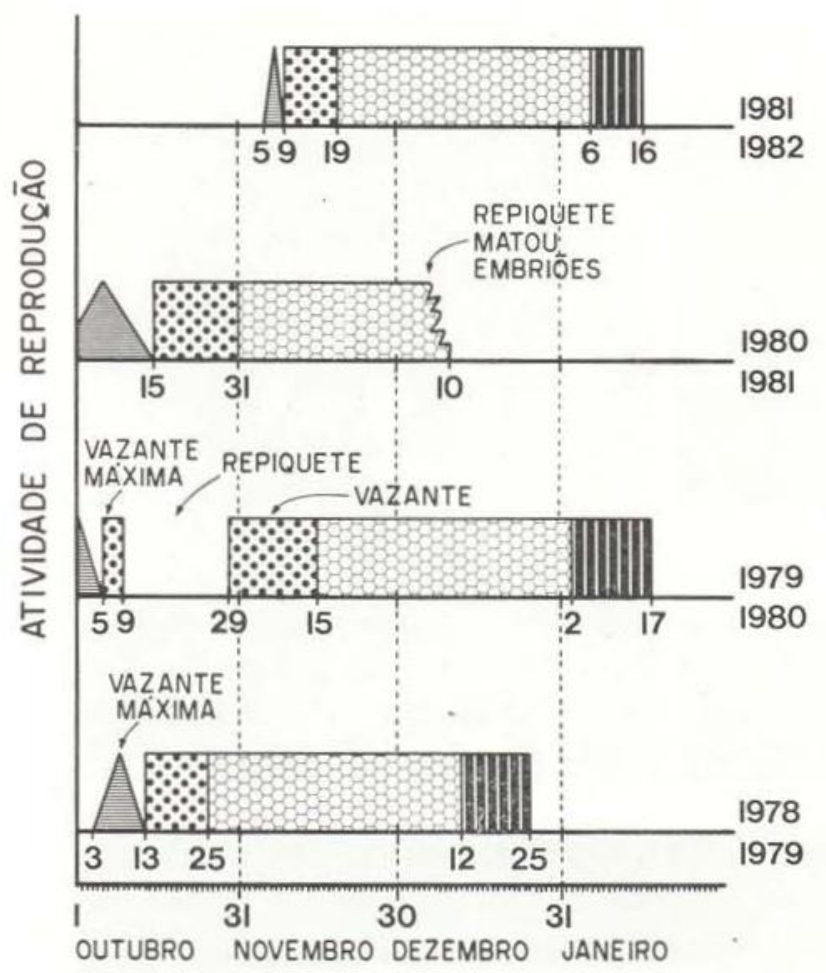

AGREGACĀO NAS ÁGUAS RASAS
$\therefore$ NIDIFICACĀO
ENCUBACĀAO
ECLOSĀO

Fig. 2 - Respostas das tartarugas ao regime de vazante do rio. A fase de agregação nas águas rasas, próximo ao local de postura, é variável, dependendo da estabilidade da vazante. Em 1979, o comportamento de nidificação foi interrompido pelo repiquete e recomeçado com a nova estabilidade da vazante em seu nível mais baixo. Em 1981, houve uma seca prolongada retardando a postura.

\section{CONCLUSÃO}

O regime de vazante com a estabilidade do nível de água, em seu nível mais baixo, parece ser a causa próxima que desencadeia 0 ritual de comportamento de nidificação de $P$. expansa.
Diferentemente de Podocnemis unifilis que age isoladamente e não é tão exigente na escolha do sítio de nidificação, $P$. expansa é social, nidificando em conjunto, e todo o grupo interagindo com o estímulo ambiental. É muito raro encontrar postura de uma $P$. expansa que tenha agido isoladamente para desovar.

\section{REFERENCIAS BIBLIOGRÁFICAS}

ALHO, C.J.R.; CARVALHO, A.G. \& PADUA, L.F.M.

1979 - Ecologia da tartaruga da Amazônia e avaliação de seu manejo na Reserva Bíológica do Trombetas. In Brasil Florestal, 9 (38): 29-47.

ALHO, C.J.R. \& PADUA, L.F.M.

1982 - Reproductive Parameters and nesting behavior of the Amazon turtle Podocnemis expansa (Testudinata: Pelomedusidae) in Brazil. In: Canadian Journal of Zoology Canadá (no prelo).

CARR, A. \& GIOVANNOLI, L.

1957 - The ecology and migrations of sea turtles. 2. Results of field work in Costa Rica, 1955. In: Amer. Mus. Novit., 1835: 1-32.

EHRENFELD, D.W

1979 - B shavior associated with nesting. In: Turtles - Perspectives and Research. (Harless \& Morlock eds.). Wiley-Inters. Public pp. 417-434.

MORISITA, M.

1959 - Measuring of the dispersion of individuals and analysis of the distribution pattern. In: Memoirs of the Faculty of Science., Kyusshu University Series E (Biology) 2: 212-235.

1962 - I-delta index, a measure of dispersion of individuals In: Researches on Pop. Ecology, 4: $1-7$.

1964 - Application of I-delta index to sampling techniques. In: Research on Pop. Ecology, 4: 43-53.

VANZOLINI, P.E.

1967 - Notes on the nesting behavior of Podocnemis expansa in the Amazon valley (Testudines, Pelomedusidae). In Pap. Avulsos, Zool., (São Paulo) 20: 191-215.

(Aceito para publicação em 23/03/82) 